\title{
Controversies in lupus: nervous system involvement
}

\author{
G A W Bruyn
}

Despite great improvements in the ability to treat systemic lupus erythematosus (SLE) nephritis, management of nervous system manifestations of patients with SLE remains unsatisfactory. Nervous system involvement occurs in about $50 \%$ of all patients at some time during the course of their illness, with an impact on their lives which can vary from insignificant to disabling. Indications that the nervous system is involved include the organic brain syndrome (disorientation, forgetfulness, disturbances of attention), seizures, chorea, stroke, and frank episodes of psychosis. Controversy as to the best approach to patients with central nervous system (CNS) SLE surrounds the pathogenesis, diagnostic difficulties, and treatment. This article focuses on these three topics.

\section{Pathogenesis}

The pathogenesis of CNS SLE leads both to the observed histopathological findings ${ }^{1-3}$ and to the clinical manifestations; at the same time it forms the main target of treatment. In a landmark study, Johnson and Richardson ${ }^{1}$ described the pathology of cerebral lupus. They found $80 \%$ of 24 postmortem brain specimens to be microscopically abnormal; multifocal microinfarcts and increased pericapillary microglial cells were the predominant abnormalities. Abnormalities of the brain vessels include a vasculopathy involving small arteries $(<100 \mu \mathrm{m})$, in addition to fibrin thrombi occluding the lumens of affected vessels (fig 1). Features of the vasculopathy include hyalinisation of the meningeal, subcortical and cortical arterioles, in addition to perivascular lymphocytic infiltrates, endothelial proliferation, thrombosis, capillary wall thickening, and vasculitis (fig 2). Vasculitis with inflammatory cells within the vessel wall was found in only three of the 24 autopsy specimens of Johnson and Richardson. Similar findings were reported in two subsequent clinicopathological studies-one performed between 1955 and 1977 on 57 patients, ${ }^{2}$ and the most recent between 1972 and $1989 .^{3}$ Infrequently, the lesions may be restricted to the cerebellum and mid-brain. ${ }^{4}$

The association of the microvascular lesions with microinfarcts suggested that occlusion of small vessels is the basis for the damage to the nervous system. While the histopathological features are straightforward, the clinical spectrum of CNS involvement is broad. Neurological manifestations include psychosis, epilepsy, coma, stroke, chorea-athetosis, neurocognitive dysfunction, cerebellar ataxia, headache, cranial neuropathy, and transverse myelitis $^{5-8}$ - a variety which is insufficiently accounted for by direct clinicopathological correlation. This is the first big controversy in CNS lupus: is one unifying disease mechanism responsible for this diversity of clinical presentations or do separate mechanisms play a role?

Hypotheses advanced to explain the spectrum of CNS manifestations associated with SLE may be divided into four categories: immune complex vasculitis; neurone reactive autoantibodies; thrombosis associated with antiphospholipid antibodies; and cytokine enhanced autoimmunity.

IMMUNE COMPLEX DEPOSITION

In contrast to the evidence available in lupus nephritis, evidence of a true vasculitis in brains of lupus patients is not consistent: data for complement dependent inflammatory injury (consumption of total haemolytic complement, and of the third and fourth components) are not consistent; ${ }^{9-11}$ high titres of DNA autoantibodies have not been found in the cerebrospinal fluid (CSF) $;{ }^{11}$ true vasculitis is found in only about $10 \%$ of patients with cerebral lupus; ${ }^{1}$ and the spectrum of CNS manifestations of lupus is unique for this disease and is not reproduced in any of the vasculitides.

Nevertheless, the lack of extensive histological evidence for a true vasculitis involving the cerebral vessels does not preclude the implication of immune complexes in the pathogenic process: pathology similar to that found in the lupus brain has been described in the coronary arteries of a mouse model of SLE, in which immune complexes appear to cause occlusion and subsequent myocardial infarction in the absence of an inflammatory response. ${ }^{12}$ Immune complexes consisting of DNA-anti-DNA complexes have been identified in the choroid plexus of patients with neuropsychiatric lupus by both immunofluorescence and electron microscopy. ${ }^{13}$ However, choroid tissue from patients without CNS involvement was not studied. Similar findings were reported in a controlled study, but choroid tissues from rheumatoid arthritis patients and from SLE patients without CNS involvement also contained immunoglobulin deposition. ${ }^{14}$ Given these findings, it might be concluded that the highly vascular choroid
8934 AD Leeuwarden The Netherlands G A W Bruyn 


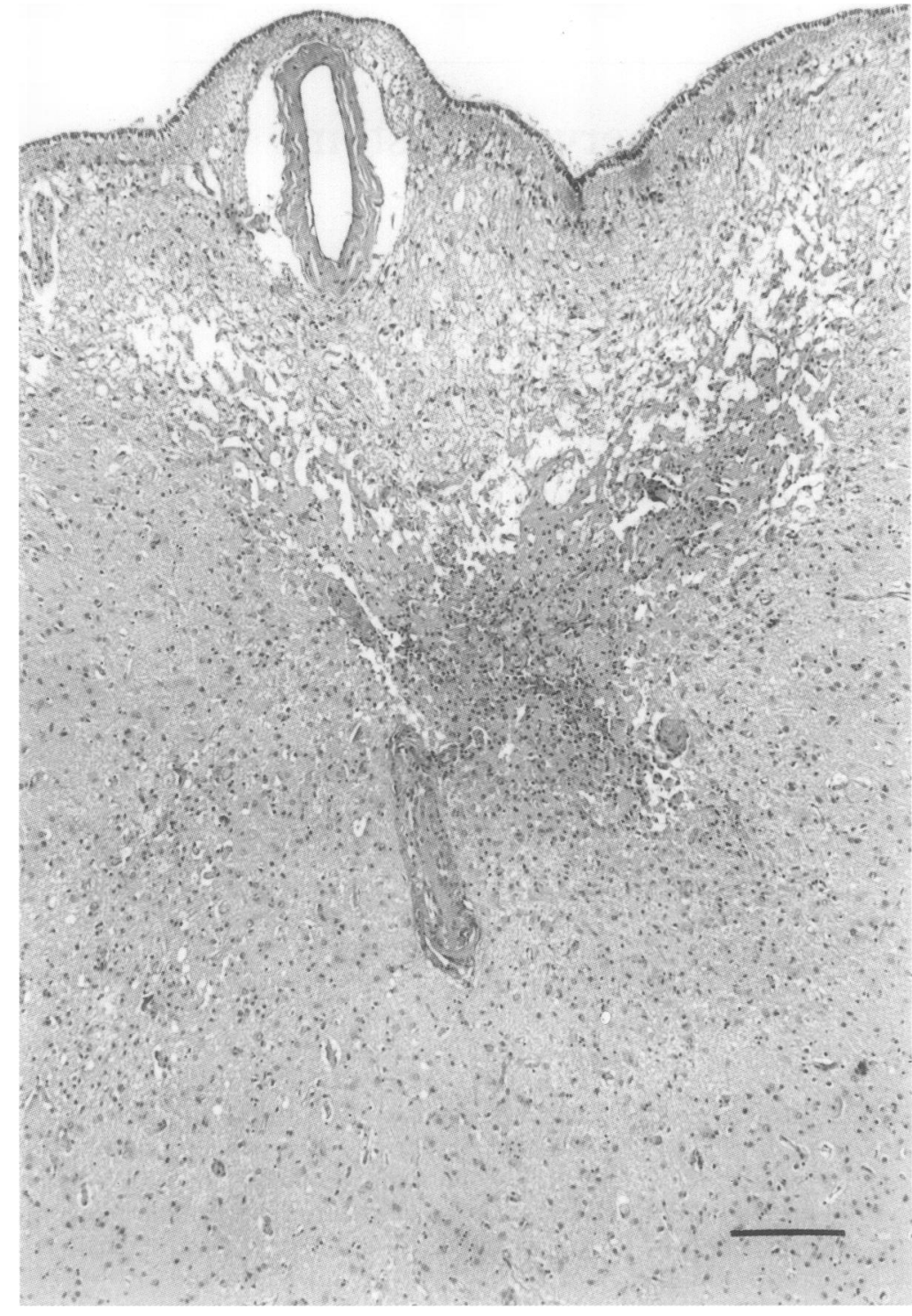

Figure 1 Central nervous system involvement in SLE: small vessel thrombosis in the subependymal cerebral tissue, with a small infarction showing an already defined clearing reaction. (Haematoxylin and eosin.) Horizontal bar represents $250 \mu \mathrm{m}$.

plexus might act as a non-specific trap for circulating immune complexes. Animal studies have shown that the permeability of the bloodbrain barrier may be altered by increased concentrations of circulating immune complexes. ${ }^{15}$ Therefore, immune complexes may play a permissive rather than a direct pathogenic role, by allowing ingress of systemically produced autoantibodies that would otherwise not gain access to the CNS. Subsequently, they might bind to nerve endings and lead to impairment of neuronal function. It has been shown that patients with neuropsychiatric SLE have disruption of the blood-brain barrier, and they may also show increased intrathecal IgG synthesis compared with lupus patients without cerebral features. ${ }^{16}$

NEURONE REACTIVE ANTIBODIES

Animal studies have supported the concept of neurone reactive antibodies directly accounting for neuropsychiatric SLE: administration of antibodies to brain constituents can induce seizures or behavioural changes. ${ }^{17}{ }^{18}$ Over the past two decades, a number of studies have reported an array of neurone reactive autoantibodies, ${ }^{11} 16192022-2628$ (table 1) found in both serum and CSF of lupus patients. As histological examinations have failed to reveal cell death as a possible mechanism, it is assumed that the autoantibodies exert their effects by interfering with the cell's ability as a responder in the neuronal network; how they do this remains uncertain. Neurone reactive autoantibodies can be divided into lymphocytotoxic antibodies (LCA) cross reactive with brain tissue, and neuronal antibodies which are targeted directly to neuronal antigens-which may be neuronal membranes or intracytoplasmic constituents of neuronal cells. Controversy exists as to the definition of lymphocytotoxicity and, as a consequence, as to the prevalence of LCA, the antigenic specificities shared by LCA and neuronal antibodies, the various reactivities of LCA, and the clinical relevance of these reactivities.

Lymphocytotoxic antibodies ( $L C A$ ). Membrane reactive autoantibodies (for example antibodies against erythrocytes, lymphocytes, and platelets) are well recognised in SLE and are responsible for the haematological features frequently found in the disease. ${ }^{21}$ Cross reactivity between LCA and brain cells was first observed by Bluestein and Zvaifler ${ }^{19}$ and subsequently confirmed by other investigators. ${ }^{16} 2021242528$ LCA have been found to correlate with various neuropsychiatric manifestations, ${ }^{19} 2324$ 26-28 but most consistently with cognitive dysfunction and visuospatial deficits. ${ }^{16}{ }^{28}$ However, the specificity of LCA for brain tissue has been questioned in some studies ${ }^{11} 1622$ in which the percentage of LCA was similar in SLE patients with and without CNS involvement. ${ }^{11} 16$ These inconsistencies may be explained not only by methodological differences, but also by the variability in defining neuropsychiatric SLE. Although it is unclear what causal role LCA play, most evidence indicates that they are not produced in reaction to brain damage but may have a specific role in the pathogenesis of cerebral lupus, particularly cognitive dysfunction and visuospatial deficit. ${ }^{1628}$

Neuronal membrane autoantibodies. Brain reactive antibodies to membrane antigens have been demonstrated in the serum of SLE patients and have been found to correlate with CNS disease. ${ }^{29}$ Bluestein et $a l^{24}$ found that IgG antineuronal antibodies in CSF, but not in serum, correlated with diffuse CNS disease, but other investigators did not confirm these findings. ${ }^{26}$ Most studies used neuroblastoma cell lines as the antigen source, but it is doubtful if those primitive tumour antigens are also present on normal brain cells. ${ }^{30}$ Antigenic variability is great: one study found an autoantibody reactivity with the $50 \mathrm{kDa}$ neuronal antigen associated with active CNS lupus in 19 of 20 patients tested. ${ }^{31}$ It is not clear if this $50 \mathrm{kDa}$ neuronal membrane antigen is similar to the $50-52 \mathrm{kDa}$ reactivity in lupus sera that contain LCA. ${ }^{28}$ Another study did not show surface antigens; ${ }^{26}$ yet another found a $97 \mathrm{kDa}$ antigen present on neuronal cells 


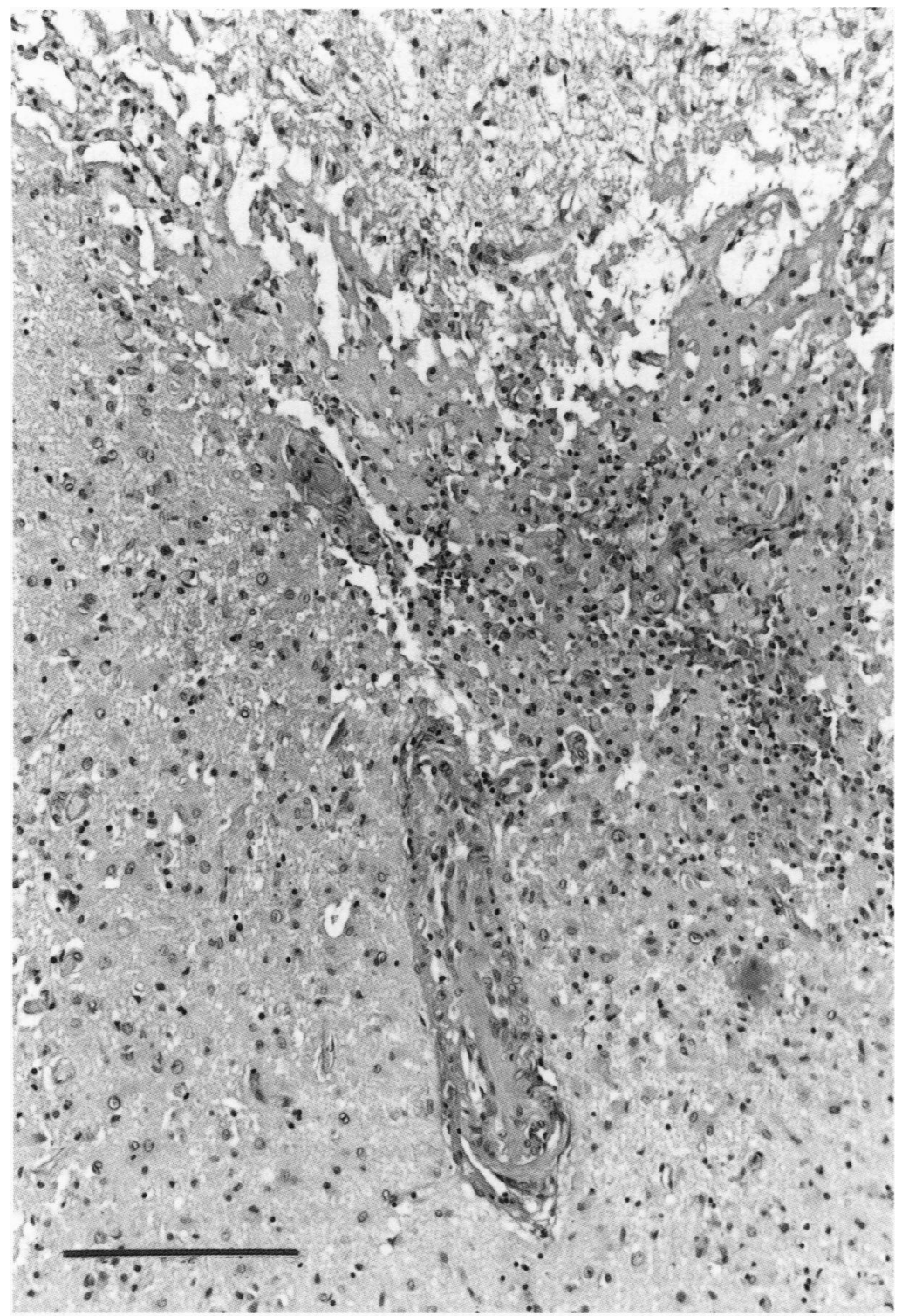

Figure 2 Detail of fig 1. Visible are, amongst others, accumulation of macrophages, astrocyte swelling, and incipient capitation. (Haematoxylin and eosin.) Horizontal bar represents $250 \mu \mathrm{m}$.

recognised by some SLE sera. ${ }^{30}$ Because of this variability some investigators have suggested alternative methods using human brain tissue to identify target antigens, which may lead to a better understanding of the role of antineuronal antibodies in the pathogenesis of cerebral SLE. ${ }^{31} 32$
Intracytoplasmic targeted antibodies. Antibodies to intracytoplasmic constituents of neuronal cells-including anti-ribosomal $P,{ }^{26}{ }^{33-36}$ antineurofilament antibodies, ${ }^{37}$ and antiRo(SS-A) or anti-La(SS-B) antibodies, ${ }^{38}$ have been found in serum and CSF of patients with lupus. Since anti-Ro(SS-A) antibodies can cause heart block, it is postulated that such antibodies may profoundly interfere with cellular processes. They may enter neuronal cells by an as yet undefined access mechanism; alternatively, they may react with neuronal membrane antigens expressing $\mathbf{P}$ protein or neurofilament epitopes. Anti-ribosomal $P$ autoantibodies also recognise epitopes on various human cells, for example human hepatoma cells, human neuroblastoma cells and, to a lesser extent, human fibroblasts. ${ }^{33}$ The presence of antigen target on nonneuronal tissue may indicate a pattern of sensitisation outside the nervous system; furthermore, autoantibodies can bind to surface $P$ antigen and affect the function of cells. These autoantibodies have been found in $90 \%$ of SLE patients with psychosis, ${ }^{26} 34$ suggesting a high specificity. However, other investigators have questioned the specificity, as they found anti-P antibodies in 50\% of SLE patients without psychosis. ${ }^{35}$ For thorough discussion of anti-P autoantibodies in CNS SLE, the reader is referred to an excellent recent review. ${ }^{36}$ Antibodies to neurofilament proteins, which form part of the cytoskeleton of neuronal cells, have been demonstrated to occur in neuropsychiatric SLE but, again, are not specific to this entity. ${ }^{37}$ They may also occur in other disorders such as Alzheimer's disease and Creutzfeldt-Jakob disease.

\section{ANTIPHOSPHOLIPID ANTIBODIES}

Antibodies to phospholipids comprise a diverse group that includes the lupus anticoagulant and the anticardiolipin autoantibodies. It has long been thought that antiphospholipid (aPL) antibodies were responsible for the noninflammatory vasculopathy characterised by thickening of the walls of small arteries as a result of intimal proliferation. The original description of the lupus anticoagulant dates back to its observation in a group of lupus patients who presented with stroke. ${ }^{39}$ Initial

Table 1 Neuronal antibodies in neuropsychiatric systemic lupus erythematosus

\begin{tabular}{|c|c|c|c|c|c|c|c|}
\hline \multirow{3}{*}{$\begin{array}{l}\text { Authors } \\
\text { Bluestein et al }{ }^{19}\end{array}$} & \multirow{3}{*}{$\begin{array}{l}\text { Year } \\
1976\end{array}$} & \multirow{3}{*}{$\begin{array}{l}\text { Assay } \\
\begin{array}{c}\text { LC assay/absorption } \\
\text { with human brain }\end{array}\end{array}$} & \multirow{3}{*}{$\begin{array}{l}\text { Type of NA } \\
\text { LCA }\end{array}$} & \multicolumn{3}{|c|}{ Cells killed or absorption (\%) } & \multirow{3}{*}{$\begin{array}{l}\text { Clinical correlation antibody/CNS disease? } \\
\text { Yes }\end{array}$} \\
\hline & & & & \multicolumn{2}{|c|}{$N P-S L E$} & \multirow{2}{*}{$\frac{\text { Non-NP-SLE }}{26}$} & \\
\hline & & & & 45 & * & & \\
\hline Bresnihan et al 20 & 1977 & $\begin{array}{l}\text { LC assay/absorption } \\
\text { with human brain }\end{array}$ & LCA & 55 & * & 30 & Yes \\
\hline $\begin{array}{l}\text { Winfield et al }{ }^{11} \\
\text { Pussell et } a l^{22}\end{array}$ & $\begin{array}{l}1977 \\
1982\end{array}$ & $\begin{array}{l}\text { LC assay } \\
\text { LC assay/absorption } \\
\text { with human brain }\end{array}$ & $\begin{array}{l}\text { LCA } \\
\text { LCA }\end{array}$ & $\begin{array}{l}50 \\
65\end{array}$ & $\underset{\star}{N S}$ & $\begin{array}{l}85 \\
41\end{array}$ & $\begin{array}{l}\text { No } \\
\text { Yes }\end{array}$ \\
\hline Long et al ${ }^{16}$ & 1990 & LC assay & LCA & 32 & NS & 23 & $\begin{array}{l}\text { Negative with overall NP-SLE; } \\
\text { positive with cognitive impairement }\end{array}$ \\
\hline Denburg et $a l^{28}$ & 1994 & T lymphocyte line & LCA & NM & & NM & $\begin{array}{l}\text { Not with overall NP-SLE; } \\
\text { significantly with visuospatial deficit }\end{array}$ \\
\hline $\begin{array}{l}\text { Wilson et } a l^{23} \\
\text { Bluestein } e t a l^{24} \\
\text { Golombek et } a l^{26} \\
\text { Kelly } e t a l^{25}\end{array}$ & $\begin{array}{l}1979 \\
1981 \\
1986 \\
1987\end{array}$ & $\begin{array}{l}\text { Neuroblastoma/MHA } \\
\text { Neuroblastoma } \\
\text { Neuroblastoma } \\
\text { Neuroblastoma/MHA }\end{array}$ & $\begin{array}{l}\text { NA } \\
\text { NA } \\
\text { NA } \\
\text { NA }\end{array}$ & $\begin{array}{l}75 \\
74 \\
57 \\
17\end{array}$ & $\begin{array}{l}\star \\
\text { NS }\end{array}$ & $\begin{array}{r}45 \\
11 \\
50 \\
8\end{array}$ & $\begin{array}{l}\text { IgG association with diffuse CNS disease } \\
\text { Association only for CSF antibody } \\
\text { No clinical correlation } \\
\text { No clinical association }\end{array}$ \\
\hline
\end{tabular}

LC = Lymphocytotoxic; LCA = lymphocytotoxic antibodies; NA = neuronal antibodies; NM= not mentioned; NP= neuropsychiatric; $M H A=$ mixed haemabsorption assay.

${ }^{\star}$ Significant difference between the two groups; NS = non-significant difference. 
studies emphasised an association with focal neuropsychiatric SLE, such as stroke, amaurosis fugax, ${ }^{40}$ and transverse myelitis. ${ }^{41}$ Subsequent studies have found an association with more diffuse manifestations of cerebral SLE, such as seizures, ${ }^{42}$ chorea ${ }^{43}$ and multiinfarct dementia ${ }^{44}$ (but not with psychosis).

The multiple features associated with aPL, known as antiphospholipid antibody syndrome (APS) are thought to be the consequence of small infarcts. Endothelial cell swelling, hyperplasia, mitotic figures, and a novel angiomatoid thrombovascular complex (not vasculitis) are the characteristic cerebral and renal histopathological features of both primary and secondary APS. ${ }^{45} 46$ It has been proposed that the endothelial swelling is caused by the incorporation of fragments of platelet thrombi into the vascular endothelium ${ }^{46}$-a process hypothetically facilitated by von Willebrand factor. ${ }^{47}$ Other plasma proteins such as $\beta 2$-glycoprotein I and prothrombin-Ca, which have a high affinity for negatively charged phospholipids, may bind to the lipid surface of endothelial cells, exposing novel epitopes and perseverating the immune response. This mechanism may activate platelets, finally resulting in thrombosis. Repetitive episodes of thrombosis in these small vessels might lead to incorporation of platelet fragments and lead to the thickening and irregularity of small vessels. ${ }^{48}$ In longstanding neuropsychiatric SLE, small vessel abnormalities may lead to the microinfarctions found at postmortem. ${ }^{1-3} 4648$

CYTOKINES

Cytokines (polypeptide products of activated lymphocytes that participate in a variety of cellular responses) may play a dual role in the development or persistence of CNS involvement in SLE. Interferons may increase the severity of autoimmune disease in animals, ${ }^{49}$ but may themselves be responsible for psychosis, as has been demonstrated in patients with hepatitis $B .^{50}$ Intrathecal synthesis of interferon alfa ${ }^{5152}$ and interleukin- $6^{53}$ (a cytokine with B cell stimulatory properties and interleukin-1 like properties) has been reported in SLE patients with CNS involvement. In the patients with psychosis, interferon concentrations in CSF were significantly greater than in SLE patients with seizures alone. ${ }^{52}$ Despite these reports offering some circumstantial evidence that cytokines may be involved in the pathogenesis of cerebral lupus, many questions remain concerning the role of cytokines in lupus; it is still not clear, for example, if cytokine concentrations are increased during a disease flare. It is evident that the role of cytokines in lupus requires further study. ${ }^{54}$

\section{Diagnosis}

In reviewing the extensive range of immunoserological, electrophysiological and neuroimaging techniques which have been investigated as possible markers of CNS lupus, it is apparent that there is still no single test which is diagnostic. Diagnosis of neuropsychiatric SLE, therefore, is a matter of clinical acumen. Selection of a test from the broad array available should take into account that a positive case may, at best, be merely supportive of the diagnosis, while a negative result does not necessarily preclude a diagnosis of cerebral lupus.

Cerebrospinal fluid (CSF) examination. CSF abnormalities are commonly found but are non-specific. Generally, both a modest pleocytosis and increased protein concentrations are found. The foremost purpose of this procedure is to rule out CNS infection; it should be borne in mind, however, that CNS pleocytosis may be absent in infection.

Neuropsychometric testing (NPT). For most clinicians, NPT has some obvious disadvantages. It is not readily available, is timeconsuming, and has no indication in an acute situation as it requires a stable patient. Cognitive impairment, however, can be identified and quantified in a standardised and repeatable manner by NPT. In this way, Carbotte et $a l^{55}$ demonstrated that $66 \%$ of 62 individuals from an unselected lupus population had cognitive impairment. Not only did more than $80 \%$ of patients with current or past neuropsychiatric involvement have abnormal neuropsychometric tests, but also $42 \%$ of those with no prior CNS symptoms were found to have cognitive dysfunction. Ginsburg et $a l^{56}$ reported on the prevalence of cognitive deficits in a group of 49 randomly selected ambulatory patients with SLE and 40 with rheumatoid arthritis. They found a significantly higher prevalence of cognitive impairment amongst the SLE patients. Subsequent studies ${ }^{57-59}$ reported a substantially lower frequency of cognitive dysfunction (about 20\%) in SLE patients, reflecting selection bias in the former studies. ${ }^{556}$

Thus NPT appears to be not only a sensitive, but also a convenient, inexpensive, and noninvasive diagnostic tool in the assessment of cognitive dysfunction in lupus, especially in that group who have vague symptoms and an absence of clinical signs. Its main disadvantage is its susceptibility to learning effects, and the influence of various confounding factors such as the influence of treatment, physical illness, and pschychological distress on cognitive function. In addition to aiding diagnosis, neuropsychiatric examination may help the lupus patient to understand better those cognitive problems encountered at home, at work, and in social situations; in this way, it can be utilised to anticipate and address difficulties in everyday functioning.

Electroencephalography (EEG). EEG is of little diagnostic value in neuropsychiatric lupus. The electroencephalographic findings are frequently abnormal, showing diffuse wave slowing without any distinctive pattern, unless focal features are apparent clinically. Diagnostic sensitivity has been reported variously as between $33 \%$ and $85 \%$ of SLE patients with CNS involvement; a figure for the diagnostic 
specificity is more difficult to define, as no large prospective controlled studies have addressed this question. The technique of quantative EEG (QEEG) has been applied in a prospective study of 52 patients with SLE. ${ }^{60}$ QEEG sensitivity appeared to be $87 \%$, whereas the specificity was $75 \%$. The technique proved to be particularly useful in the subgroup that is the most difficult to assess, namely those with various forms of affective disorders and depression in the absence of neurological signs. Since this technique is not available in the majority of hospitals, experience is limited.

Angiography. Cerebral angiography is an insensitive diagnostic technique in CNS lupus, except where symptoms or signs of major vessel haemorrhage, thrombosis, or vasculitis develop. ${ }^{61}$ The procedure may be helpful before operation when cerebral bleeding has occurred. As angiography is an invasive technique with low sensitivity, it is not used routinely in the assessment of neuropsychiatric SLE.

Computed tomography (CT). The first CT scanning studies in cerebral lupus were conducted in the late 1970s and early $1980 \mathrm{~s}^{62-64} \mathrm{CT}$ is most useful in detecting gross morphological abnormalities such as large intracranial infarcts, intracranial haemorrhages, and cerebral atrophy. It is unclear if the cerebral atrophy is caused by the disease itself or by glucocorticosteroid therapy. As the predominant neuropathology in neuropsychiatric lupus is that of microinfarction, CT is frequently normal, even in the presence of focal syndromes such as cerebrovascular accidents or focal seizures. ${ }^{63}$

Magnetic resonance imaging (MRI). MRI is more sensitive than CT in demonstrating particular morphological abnormalities such as oedema and small infarcts. ${ }^{65-70}$ Three predominant patterns of MRI abnormalities are recognised: irreversible high intensity lesions compatible with cerebral infarction, multiple hyperintense areas of the white matter, probably representing microinfarctions and which are associated with aPL, ${ }^{69} 70$ and focal hyperintensity of the grey matter. It is noteworthy that the grey matter abnormalities may be reversible with clinical improvement, ${ }^{67}{ }^{68}$ suggesting resolution of oedema. In one study of 28 SLE patients with acute CNS events, cranial MRI scans were obtained within a month from the onset of symptoms. ${ }^{68}$ In all those patients with focal symptoms, MRI was able to detect cerebral lesions; CT scanning detected the lesions in only $38 \%$ of them. MRI showed lesions in $100 \%$ of episodes of seizures, but in patients demonstrating organic brain syndromes or psychosis it had a sensitivity of only $20 \%$.

Compared with CT, MRI is much the more sensitive method of detecting focal lesions in the brain of symptomatic SLE patients. Limitations are the poor specificity of the lesions found on MRI-one cannot make the diagnosis of cerebral SLE from radiographic findings alone. This may pose a problem in differentiating some white matter lesions seen in SLE patients from those found in patients with ischaemic cerebral disease or multiple sclerosis.

Radionuclide scanning. After the report of 90-100\% abnormal technetium brain scans in a group of lupus patients with active CNS disease, ${ }^{71}$ this technique subsequently became obsolete until recently, when single photon emission computed tomography (SPECT) proved worthwhile in cerebral lupus. ${ }^{72}$ In a study of 20 patients with SLE who were clinically suspected to have 'active' neurological involvement, Nossent et al found a sensitivity of almost $90 \%$, but a low specificity of $33 \% .^{73}$ More recently Rubbert et al showed an abnormal cortical perfusion in $90 \%$ of patients with mild symptoms of CNS disease (cognitive deficits) compared with $10 \%$ of SLE patients without CNS symptoms. ${ }^{74}$ These studies support the notion that, pending validation, SPECT may become an objective tool in differentiating mild CNS disease in lupus from functional conditions such as depression.

Positron emission tomography (PET). PET detects reduced cerebral metabolism with the use of radiolabelled deoxyglucose. PET scanning has been able to detect abnormalities of glucose uptake and a localised disturbance of cerebral blood flow in active neuropsychiatric lupus. ${ }^{75}$ Two patterns are recognised: focal glucose hypometabolism, and a diffuse non-homogeneous distribution pattern of increased and decreased glucose metabolism. In a study of 10 SLE patients with neurological symptoms and three patients with no neurological involvement, PET scanning showed abnormalities in all 10 with active involvement, but was normal in the three other patients; the pathological changes on PET corresponded with clinical features ${ }^{76}$ Because PET scanning requires the proximity of a cyclotron, its clinical availability will remain limited, and it will therefore not easily find a place in the clinical management of lupus.

\section{Management}

The management of cerebral lupus requires that the presence of cerebral lupus is established and its severity assessed. Sometimes forgotten is the fact that the most frequent cause of central nervous system manifestations in lupus is not the lupus itself, but infection. Infection of the CNS should be vigorously sought and treated in all cases. In addition, factors such as hypertension should be under control. The ability unequivocally to establish the presence and severity of cerebral lupus remains a mission yet unresolved by the rheumatology community. Because the revised ARA criteria ${ }^{77}$ are largely inadequate in defining CNS SLE, investigators have concentrated on standardising a classification and system of definition of neurological events. ${ }^{78}$ However, until strict criteria for recognition of CNS SLE are laid down, reports correlating clinical findings with pathology, serological parameters, and radiology may be biased and unreliable, and it will not be possible to test treatment modalities rigorously. 
It is not surprising, therefore, that uncertainty and controversy dominate the field of management of cerebral lupus. Should an SLE patient presenting with stroke be treated in a totally different way than a patient with organic brain syndrome? Merely for practical reasons, it might be sensible to classify CNS SLE into separate groups with various manifestations. ${ }^{6}$

No controlled study of any treatment strategy has so far been conducted in neuropsychiatric lupus. The principles of treatment of cerebral lupus lupus are triple: anticoagulants, corticosteroids, and immunosuppressives (table 2). Anticoagulants should be given for manifestations associated with hypercoagulability. Steroids are administered to reduce inflammation and the immune response. Finally, immunosuppressives, for example cyclophosphamide and azathioprine, suppress circulatory $\mathrm{B}$ and $\mathrm{T}$ lymphocytes, and autoantibody formation by $\mathrm{B}$ lineage cells in lymphoid tissues.

Anticoagulation for whom? Since the elucidation of the role of antiphospholipid antibodies in thrombotic manifestations in SLE patients, ${ }^{39} 41$ growing agreement on anticoagulation has emerged steadily. Lupus patients simply with presence of these antibodies are currently not considered to be at high risk of developing thrombotic events and do not receive prophylactic anticoagulation. Patients with SLE and a history of bland stroke, however, have a $69 \%$ chance of a recurrent stroke. ${ }^{79}$ Therefore, recurrent cerebral thrombotic events-whether associated with antiphospholipid antibodies or not-are now important indications for initiating anticoagulation therapy. ${ }^{79}{ }^{80}$ In all cases of stroke, cardiogenic emboli should be considered as possible causes as they form a major cause of stroke in lupus. Although consensus has not yet been reached and clinical experience is largely lacking, other nervous system manifestations associated with antiphospholipid antibodies (seizures, ${ }^{42}$ chorea, ${ }^{43}$ migraine,${ }^{80}$ or transverse myelitis ${ }^{41}{ }^{81}$ ) may become important treatment indications for anticoagulant therapy in the very near future. It is not known if patients with organic brain syndrome may benefit from anticoagulation; as their prognosis is generally favourable, ${ }^{59}$ administration of any medication, including anticoagulants, is not imperative.

The best mode and duration of anticoagulation is yet unknown. Possible options include low dose aspirin ( $75 \mathrm{mg}$ daily), warfarin, or subcutaneous heparin. In addition, hydroxychloroquine has been shown to possess

Table 2 Uncertainties of therapy in neuropsychiatric lupus erythematosus

\begin{tabular}{llll}
\hline Feature & Anticoagulation & Corticosteroids & Cyclophosphamide \\
\hline OBS & + & + & - \\
Seizures & ++ & ++ & $?$ \\
Acute psychosis & - & ++ & ++ \\
Coma & - & ++ & ++ \\
Stroke (bland) & ++ & + & - \\
Stroke (bloody) & - & + & - \\
Chorea & ++ & ++ & ++ \\
Transverse myelitis & + & ++ & - \\
Migraine & + & $?$ & ++ \\
\hline
\end{tabular}

OBS $=$ Organic brain syndrome; $++=$ worthwhile therapy; $+=$ probably worthwhile therapy $?=$ uncertain effect; $-=$ probably not effective or contraindicated. anticoagulant properties. Antiplatelet coagulants such as aspirin may be ineffective in prevention of recurrent thrombosis in patients with antiphospholipid antibodies, as retrospective studies have shown that warfarin or coumarin is more effective than aspirin therapy; ${ }^{82} 83$ data on low molecular weight heparin injections were too limited for any conclusions to be drawn. ${ }^{82}$ Therefore, in patients with major thrombosis such as stroke, warfarin is currently the preferred choice of treatment; as an additional advantage, it is effective against cardiogenic emboli. In order to be effective, however, warfarin therapy should be highly intensive (at an international normalised ratio of between 2.5 and 4.0 ); it is obvious that such an anticoagulation level is not without risk for major bleeding. Duration of therapy should be lifelong, as recurrence of thrombosis may occur after cessation of the anticoagulation. ${ }^{83}$

Antimalarial drugs also have an anticoagulant effect. Withdrawal of antimalarial treatment was studied in patients with SLE in a randomised, placebo controlled clinical trial. ${ }^{84}$ Five of the patients $(23 \%)$ taking placebo and one of the patients $(4 \%)$ continuing to take hydroxychloroquine had severe exacerbations of disease activity that prompted their withdrawal from the study. Amongst the exacerbations in the placebo group, one patient developed transverse myelitis requiring treatment with high dose corticosteroids. Such observations may focus attention on the place of antimalarials in the order of choice of therapy, which should perhaps be reconsidered in the future.

Corticosteroids form a mainstay in the treatment of SLE, although this dogma itself is largely empirical. In all cases in which antineuronal antibodies may play a role (cognitive dysfunction and psychosis) its use should be considered. Patients with vasculitis should also be treated with corticosteroids, but nervous system vasculitis occurs infrequently. As steroids reduce oedema around infarcted areas, patients with acute bland stroke may improve with steroids, but the administration of corticosteroids for the prevention of stroke is justified only when there is sufficient systemic activity, ${ }^{79}$ as they do not predictably decrease antiphospholipid antibody concentrations in plasma, nor do they protect against subsequent strokes. ${ }^{679}$ High dose steroids are indicated in cases of coma, seizures, psychosis, chorea, and transverse myelitis, but even in these serious conditions the effect of corticosteroid therapy is unpredictable, as controlled studies have not been performed. The starting dose of corticosteroids in cerebral lupus is also not known, but according to most authors is probably high ( $\geq 1 \mathrm{mg} / \mathrm{kg}$ per day for four to six weeks before gradual reduction). Intravenous pulse therapy has been extensively used in the treatment of lupus since the original description of its use in SLE nephritis. ${ }^{85}$ There have been several reports of the use of pulse steroid therapy in the treatment of non-renal SLE, including neuropsychiatric lupus. ${ }^{86-89}$ Eyanson et al reported two acutely ill patients 
who failed to respond to oral glucocorticoid therapy, but who responded dramatically to intravenous methylprednisolone pulse therapy. ${ }^{86}$ Dutton et al reported three women with acute retrobulbar optic neuritis who responded to intravenous methylprednisolone therapy; ${ }^{87}$ the diagnosis of SLE, however, was not clearly established. More recently, new perspectives have arisen for the treatment of the rare complication, transverse myelitis, by pulse steroids followed by cyclophosphamide for a mean of six months. ${ }^{88}$

Controversy attends the possible role of corticosteroids in the induction of psychosis and the facilitation of infection. Sergent $e t a l^{89}$ retrospectively examined the effect of corticosteroids in 28 patients with 52 episodes of nervous system manifestations and found that 14 patients had 15 episodes of functional psychosis, possibly attributable to treatment. Five of the nine deaths in that study were attributable to infection. Since the patients received mean prednisone doses of more than $100 \mathrm{mg} /$ day for prolonged periods, side effects should be anticipated. Glucocorticoids are now prescribed in much smaller doses than formerly used. ${ }^{7}$ In the study by O'Connor, ${ }^{90}$ of 11 previously psychotic patients who subsequently received steroids, only three had a recurrence of their psychoses. The eight patients who had no further psychotic episodes received essentially the same amount of corticosteroids as they had had at the time of their psychoses. That paper clearly showed that lupus patients are particularly prone to develop psychotic episodes independently of steroid therapy, although the latter may play some part.

Cytotoxic agents have been extensively studied in renal lupus during the past two decades. Treatment comprising oral azathioprine in combination with prednisone was better than prednisone alone in the management of lupus nephritis. No data exist on this drug in the management of CNS lupus. Another agent, cyclophosphamide, has also proved to be effective in lupus nephritis in combination with prednisone. In one open prospective trial, the effect of monthly intravenous infusions of cyclophosphamide to nine patients with lupus nephritis, cerebral lupus, or both, was studied; ${ }^{91}$ although CNS disease improved in a small number of patients, there were insufficient data to permit conclusions about the treatment of the neurological disease. Another study was of refractory CNS lupus in nine patients, six of whom had been unresponsive to high dose steroid therapy. ${ }^{92}$ Six patients had a complete and two a partial recovery; side effects were common, however. From these studies and others, ${ }^{7}$ and from unpublished personal observations, it seems that intravenous pulse cyclophosphamide therapy may be the best therapy for lupus patients with progressive deterioration in level of consciousness, ${ }^{7}$ acute psychosis or coma ${ }^{91}$ (GRV Hughes, personal communication). Furthermore, in combination with intravenous pulse methylprednisolone it is the treatment of choice for transverse myelitis. ${ }^{88}$
Experimental therapies, including low dose methotrexate, cyclosporin, plasmapheresis, total lymphoid irradiation, anti-idiotypic antibodies, and intravenous IgG are the subject of too limited experience for it to be possible to recommend them at the present time.

\section{Summary}

What have we learned about CNS lupus in recent years? An enormous amount of knowledge on pathophysiology of antiphospholipid antibodies, in particular, has been gathered. Although hard evidence of a direct pathogenetic role of these antibodies in cerebral lupus is still lacking, it is generally felt that the multiple microinfarctions found in the brains of lupus patients are related to their presence. Better understanding of the pathogenesis of cerebral lupus will come from the study of experimental models, as it has been possible to develop an antiphospholipid antibody syndrome in mice. ${ }^{93}$

Because no specific laboratory test for CNS lupus is yet available, diagnosing the condition remains a challenge to every clinician. Techniques including neuropsychometric testing, quantitative EEG, and SPECT scans have taught us more about cognitive dysfunction and psychosis in patients with SLE. These categories remain the most difficult to define.

The concept of hypercoagulability in SLE patients has diverted the direction of therapy from immunosuppression towards anticoagulation. It is of utmost importance that randomised trials are commenced in order to determine the optimal mode of anticoagulation for various groups of lupus patients. It will be necessary to conduct such trials under strict inclusion criteria, based on well defined patient categories. Such an enterprise will require international co-operation of investigators.

The specimens for microscopy were kindly provided by Ziekenhuis Leiden.

1 Johnson R T, Richardson E P. The neurological manifestations of systemic lupus erythematosus. Medicine tations of systemic lupus

2 Ellis S G, Verity M A. Central nervous system involvement in systemic lupus erythematosus: a review of neuropathologic findings: 57 cases 1955-1977. Semin Arthritis Rheum 1979; 8: 212-21

3 Hanly J G, Walsh N M G, Sangalang V. Brain pathology in systemic lupus erythematosus. $\mathcal{F}$ Rheumatol 1992; 19: $732-41$

4 Smith R W, Ellison D W, Jenkins E A, Gallagher P J, Cawley M I D. Cerebellum and brainstem vasculopathy in systemic lupus erythematosus: two clinico-pathological cases. Ann Rheum Dis 1994; 53: 327-30.

5 Mitsias P, Levine S R. Large cerebral vessel occlusive disease in systemic lupus erythematosus. Neurology 1994; 44: 385-93.

6 Futrell N, Schultz L R, Millikan C. Central nervous system disease in patients with systemic lupus erythematosus. Neurology 1992; 42: 1649-57.

7 Sibley J T, Olszynski W P, Decoteau W E, Sundaram M B. The incidence and prognosis of central nervous system disease in systemic lupus erythematosus. $\mathcal{f}$ Rheumatol 1992; 19: 47-52.

8 Hochberg M C, Boyd R E, Ahearn J M, et al. Systemic lupus erythematosus: a review of clinico-laboratory features and immunogenetic markers in 150 patients with emphasis on demographic subsets. Medicine (Baltimore) 1985; 64: 285-95.

9 Jongen P J H, Boerbooms A M T, Lamers K J B, Raes B C, Vierwinden G. Diffuse CNS involvement in systemic lupus erythematosus: Intrathecal synthesis of the 4th component of complement. Neurology 1990; 40: 1593-6. 
10 Hadler N M, Gerwin R D, Frank M M, Whitaker J N, Baker M, Decker J L. The fourth component of complement in the cerebrospinal fluid in SLE. Arthritis Rheum 1973; 16: 507-21.

11 Winfield J B, Brunner C M, Koffler D. Serologic studies in patients with systemic lupus erythematosus and central nervous system dysfunction. Arthritis Rheum 1978; 21: 289-94

12 Hang L M, Izui S, Dixon F J. (NZBxBXSB)F1 hybrid: a model of acute lupus and coronary vascular disease with myocardial infarction. $\mathcal{F}$ Exp Med 1981; 36: 154-6.

13 Atkins C J, Kondon J J, Quismorio F P, Friou G J. The choroid plexus in systemic lupus erythematosus. Ann Intern Med 1972; 76: 65-72.

14 Boyer R S, Sun N C J, Verity A, Nies K M, Louie J S. Immunoperoxidase staining of the choroid plexus in
systemic lupus erythematosus. $\mathcal{f}$ Rheumatol 1980; 7: $645-50$.

15 Harbeck R J, Hoffman A A, Hoffman S A, Shucard D W. Cerebrospinal fluid and the choroid plexus during acute immune complex disease. Clin Immunol Immunopath 1979; 13: 413-25.

6 Long A A, Denburg S D, Carbotte R M, Singal D P, Denburg J A. Serum lymphocytotoxic antibodies and neurocognitive function in systemic lupus erythematosus. Ann Rheum Dis 1990; 49: 249-53.

17 Karpiak S E, Graf L, Rapport M M. Antiserum to brain gangliosides produces rect

18 Karpiak S E Serokosz M, Rapport M M. Effects of antisera to $S-100$ protein and to synaptic membrane fraction in to $\mathrm{S}-100$ protein and to synaptic membrane fraction in maze p

19 Bluestein H G, Zvaifler N J. Brain-reactive lymphocytotoxic antibodies in the serum of patients with systemic lupus erythematosus. $\mathcal{F}$ Clin Invest 1976; 57: 509-16.

20 Bresnihan B, Oliver M, Grigor G, Hughes G R V. Brain reactivity of lymphocytotoxic antibodies in systemic lupus erythematosus with and without cerebral involvement. Clin Exp Immunol 1977; 30: 333-7.

21 Bresnihan B, Oliver M, Williams B, Hughes G R V. An antineuronal antibody cross-reacting with erythrocytes and lymphocytes in systemic lupus erythematosus. Arthritis Rheum 1979; 22: 313-20.

22 Pussell B A, Blyth F, Charlesworth J A. Failure to detect brain reactivity of lymphocytotoxins in cerebral lupus. Clin Exp Immunol 1982; 47: 133-7.

23 Wilson H A, Winfield J B, Lahita R G, Koffler D. Association of IgG anti-brain antibodies with central nervous dysfunction in systemic lupus erythematosus. Arthritis Rheum 1979; 22: 458-62.

24 Bluestein H G, Williams G W, Steinberg A D. Cerebrospinal fluid antibodies to neuronal cells: association with neuropsychiatric manifestations of systemic lupus erythematosus. Am f Med 1981; 70: 240-6.

25 Kelly M C, Denburg J A. Cerebrospinal fluid immunoglobulins and neuronal antibodies in neuropsychiatric systemic lupus erythematosus and related conditions. f Rheumatol 1987; 14: 740-4.

26 Golombek S J, Graus F, Elkon K B. Autoantibodies in the cerebrospinal fluid of patients with systemic lupus erythematosus. Arthritis Rheum 1986; 29: 1090-7.

27 Hanly J G, Walsh N M, Fisk J D, et al. Cognitive impairment and autoantibodies in systemic lupus erythematosus. $B r$ F Rheumatol 1993; 32: 291-9.

28 Denburg S D, Behmann S A, Carbotte R M, Denburg J A Lymphocyte antigens in neuropsychiatric systemic lupus erythematosus. Relationship of lymphocyte antibody specificities to clinical disease. Arthritis Rheum 1994; 37: 369-75.

29 How A, Dent P B, Liao S-K, Denburg J A. Antineuronal antibodies in neuropsychiatric systemic lupus

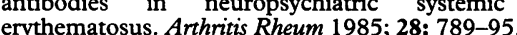

30 Hanly J G, Rajaraman S, Behmann S, Denburg J A. A nove neuronal antigen identified by sera from patients with neuronal antigen identified by sera from patients with
systemic lupus erythematosus. Arthritis Rheum 1988; 31: 1492-9.

31 Hanson V G, Horowitz M, Rosenbluth D, Spiera H, Puszkin S. Systemic lupus erythematosus patients with central nervous system involvement show autoantibodies to a $50-\mathrm{kD}$ neuronal membrane protein. $\mathcal{F}$ Exp Med 1992; 176: $565-73$

32 Hanly J G, Hong C. Antibodies to brain integral membrane proteins in systemic lupus erythematosus. F Immunol Meth 1993; 161: 107-18.

33 Koren E, Reichlin M W, Koscec M, Fugate R, Reichlin M. Autoantibodies to the ribosomal $P$ proteins react with a plasma membrane-related target on human cells. $7 \mathrm{Cl}$ Invest 1992; 89: 1236-41.

34 Bonfa E, Golombek S J, Kaufman L D, et al. Association between lupus psychosis and anti-ribosomal P protein antibodies. $N$ Engl $₹$ Med 1987; 317: 265-71.

35 Van Dam A, Nossent H, De Jong J, et al. Diagnostic value of antibodies against ribosomal phosphoproteins. A cross sectional and longitudinal study. $\mathcal{f}$ Rheumatol 1991; 18: sectional 1026 - 34

36 Teh L, Isenberg D A. Antiribosomal P protein antibodies in systemic lupus erythematosus. Arthritis Rheum 1994 37: $307-15$.

37 Robbins M L, Kornguth S E, Bell C L, et al. Antineurofilament antibody evaluation in neuropsychiatric systemic lupus erythematosus. Arthritis Rheum 1988; 31: 623-8.

38 Mevorach D, Raz E, Shalev O, Steiner I, Ben-Chetrit E. Complete heart block and seizures in an adult with systemic lupus erythematosus. Arthritis Rheum 1993; 36: 259-62.

39 Boey M L Colaco M B, Gharavi A E, Elkon K B, Loizou S, Hughes G R V. Thrombosis in systemic lupus erythematosus: striking association with the presence of circulating lupus anticoagulant. BMF 1983; 287: 1021-3.

40 Digre K B, Durcan F J, Branch D W, Jacobson D M Varner M W, Baringer J R. Amaurosis fugax associated with antiphospholipid antibodies. Ann Neurol 1989; 25: 228-32.

41 Alarcon-Segovia D, Deleze M, Oria C, et al. Antiphospholipid antibodies and the antiphospholipid syndrome in systemic lupus erythematosus. A prospective analysis of 500 consecutive cases. Medicine (Baltimore) 1989; 68: 353-65.

42 Herranz M T, Rivier G, Khamashta M A, Blasrer K U Hughes G R V. Association between antiphospholipid antibodies and epilepsy in patients with systemic lupus antibodies and epilepsy in patients with system

43 Asherson R A, Derksen R HW M, Harris E N, et al. Chorea in systemic lupus erythematosus and lupus-like disease: association with antiphospholipid antibodies. Semin Arthritis Rheum 1987; 16: 253-9.

44 Asherson R A, Mercy D, Philipis G, et al. Recurrent strok and multi-infarct dementia in SLE associated with antiphospholipid antibodies. Ann Rheum Dis 1987; 46: 605-11.

45 Westerman E M, Miles J M, Backonja M, Sandstrom W R. Neuropathologic findings in multiinfarct dementia associated with aCL. Arthritis Rheum 1992; 35: 1038-41.

46 Hughson M D, McCarty G A, Sholer C, Brumback M D. Thrombotic cerebral arteriopathy in patients with the antiphospholipid syndrome. Mod Pathol 1993; 6: 644-53.

47 Lindsey N J, Dawson R A, Henderson F I, Greaves M Hughes G R V. Stimulation of von Willebrand factor antigen release by immunoglobulin from thrombosis prone patients with systemic lupus erythematosus and the anti-phospholipid syndrome. F Rheumatol 1993; 32: 123-6.

48 Ellison D, Gatter K, Heryet A, Esiri M. Intramural platelet deposition in cerebral vasculopathy of systemic lupus erythematosus. $\mathcal{F}$ Clin Pathol 1993; 46: 37-40

49 Adam $C$, Thoua $Y$, Ronco $P$, Verroust $P$, Tovey $M$, Morel-Marover L. The effect of exogenous interferon: acceleration of autoimmune and renal disease in NZB/W F1 mice. Clin Exp Immunol 1980; 40: 373-82.

50 McDonald E M, Mann A H, Thomas H C. Interferon as mediators of psychiatric morbidity: an investigation in a trial of recombinant alpha-interferon in hepatitis- $B$ carriers. Lancet 1987; ii: 1175-7.

51 Lebon P, Lenoir G R, Fischer A, Lagrue A. Synthesis of intrathecal interferon in systemic lupus erythematosus with neurological complications. $B M F$ 1983; 287: 1165-7.

52 Shiozawa S, Kuroki Y, Kim M, Hirohata S, Ogijno T. Interferon-alpha in lupus psychosis. Arthritis Rheum 1992 35: 417-22.

53 Hirohata S, Miyamoto T. Elevated levels of interleukin-6 in cerebrospinal fluid from patients with systemic lupus erythematosus and central nervous system involvement. Arthritis Rheum 1990; 33: 644-9.

54 Gordon C, Emery P. Cytokines and the acute phase response in SLE. Lupus 1993; 2: 345-7

55 Carbotte R M, Denburg S D, Denburg J A. Prevalence of cognitive impairment in systemic lupus erythematosus. f Nerv Ment Dis 1986; 174: 357-64

56 Ginsburg K S, Wright E A, Larson M G, et al. A controlled study of the prevalence of cognitive dysfunction in randomly selected patients with systemic lupus erythematosus. Arthritis Rheum 1992; 35: 776-82.

57 Hanly J G, Fisk J D, Sherwood G, Jones E, Verrier Jones J, Eastwood B. Cognitive impairment in patients with systemic lupus erythematosus. $f$ Rheumatol 1992; 19: $562-7$

58 Hay E M, Black D, Huddy A, et al. Psychiatric disorder and cognitive impairment in systemic lupus erythematosus. Arthritis Rheum 1992; 35: 411-6.

59 Hay E M, Huddy A, Black D, et al. A prospective study of psychiatric disorder and cognitive function in systemic lupus erythematosus. Ann Rheum Dis 1994; 53: 298-303.

60 Ritchlin C T, Chabot R J, Alper K, et al. Quantative electroencephalography. A new approach to the diagnosis of cerebral dysfunction in systemic lupus erythematosus. Arthritis Rheum 1992; 35: 1330-42.

61 Sanders E A J M, Hogenhuis L A H. Cerebral vasculitis as presenting symptom of systemic lupus erythematosus. Acta Neurol Scand 1986; 74: 75-7.

62 Bilaniuk L T, Patel S, Zimmerman R A. Computed tomography of systemic lupus erythematosus. Radiology 1977; 124: 119-21.

63 Gonzalez-Scarano F, Lisak L B, Bilaniuk L T Zimmerman R A, Arkins P C, Zweiman B. Cranial computed tomography in the diagnosis of systemic lupus erythematosus. Ann Neurol 1979; 5: 158-65.

64 Carette S, Urowitz M B, Grosman H, St Louis E. Cranial computerized tomography in systemic lupus erythematosus. $¥$ Rheumatol 1992; 9: 855-9.

65 Vermess $M$ Bernstein R M Bydder G M, Steiner R E Young I R, Hughes G R V. Nuclear magnetic resonance (NMR) imaging of the brain in systemic lupus erum imaging of the brain in systemic lupus

66 Sewell K L, Linch A, Aranow C B, Grayzel A I. Magnetic resonance imaging versus computed tomographic scanning in neuropsychiatric SLE. Am $\mathcal{F}$ Med 1989; 86: 625-6. 
67 Sibbitt W L, Sibbitt R R, Griffey R H, Eckel C, Bankhurst A D. Magnetic resonance and computed tomographic imaging in the evaluation of acute tomographic imaging in the evaluation of acute Ann Rheum Dis 1989; 48: 1014-22.

68 McCune W J, MacGuire A, Aisen A, Gebarski S. Identification of brain lesions in neuropsychiatric systemic lupus erythematosus by magnetic resonance imaging. Arthritis Rheum 1988; 31: 159-66.

69 Molad Y, Sidi Y, Gornish M, Lerner M, Pinkhas J, Weinberger A. Lupus anticoagulant: correlation with magnetic resonance imaging of brain lesions. $\mathcal{f}$ Rheumatol 1992; 19: 556-61.

70 Ishikawa S, Ohnishi K, Miyachi Y, Ishizaka H. Cerebral lesions in systemic lupus erythematosus by magnetic resonance imaging. Relationship to anticardiolipin antibody. F Rheumatol 1994; 21: 87-90.

71 Bennahum D A, Messner R P, Shoop J D. Brain scan findings in central nervous system involvement by systemic lupus erythematosus. Ann Intern Med 1974; 81: 763-5.

72 Kushner M J, Tobin M, Fazekas F, et al. Cerebral blood flow variations in CNS lupus. Neurology 1990; 40: 99-102.

73 Nossent J C, Hovestadt A, Schönfeld D H W, Swaak A J G. Single-photon-emission computed tomography of the brain in the evaluation of cerebral lupus. Arthritis Rheum 1991; 34: 1397-403.

74 Rubbert A, Marienhagen J, Pirner K, et al. Single-photonemission computed tomography analysis of cerebral blood flow in the evaluation of central nervous system involvement in patients with systemic lupus erythematosus. ment in patients with systemic lup
Arthritis Rheum 1993; 36: 1253-62.

75 Hiraiwa $M$, Nonaka C, Toshiaki A, Masaaki I. PET in systemic lupus erythematosus: relation of cerebral vasculitis to PET findings. Am $\mathcal{f}$ Neuroradiol 1983; 4: 541-3.

76 Stoppe G, Wildhagen K, Seidel J W, et al. Positron emission tomography in neuropsychiatric lupus erythematosus. Neurology 1990; 40: 304-6.

77 Tan E M, Cohen A S, Fries J F, et al. The 1982 revised criteria for the classification of systemic lupus erythematosus. Arthritis Rheum 1982; 25: 1271-7.

78 Singer J, Denburg J A. Diagnostic criteria for neuropsychiatric systemic lupus erythematosus: the results of a consensus meeting. F Rheumatol 1990; 17: 1397-402.

79 Futrell N, Millikan C. Frequency, etiology, and prevention of stroke in patients with systemic lupus erythematosus. Stroke 1989; 20: 583-91.
80 Asherson R A, Khamashta M A, Gil A, et al. Cerebrovascular disease and antiphospholipid antibodies in systemic lupus erythematosus, lupus-like disease, and the primary antiphospholipid syndrome. Am $f$ Med 1989; 86: primary

81 Lavalle C, Pizarro S, Drenkard C, Sanchez-Guerrero J, Alarçon-Segovia D. Transverse myelitis: a manifestation of SLE associated with antiphospholipid antibodies. f Rheumatol 1990; 17: 34-7.

82 Rosove M H, Brewer P M C. Antiphospholipid thrombosis: clinical course after the first thrombotic event in 70 patients. Ann Intern Med 1992; 117: 303-8.

83 Derksen $R$ H W $M$, De Groot $P$ G, Kater L, Nieuwenhuis H K. Patients with antiphospholipid antibodies and venous thrombosis should receive long term anticoagulant treatment. Ann Rheum Dis 1993; 52: 689-92.

84 Canadian Hydroxychloroquine Study Group. A randomized study of the effect of withdrawing hydroxyrandomized study of the effect of withdrawing hydroxyN Engl f Med 1991; 324: $150-4$.

85 Cathcart E S, Idelson B A, Scheinberg M A, Couser W G. Beneficial effects of methylprednisolone pulse therapy in diffuse proliferative nephritis. Lancet 1976; i: 163-6.

86 Eyanson S, Passo M H, Aldo-Benson M A, Benson M D. Methylprednisolone pulse therapy for nonrenal lupus erythematosus. Ann Rheum Dis 1980; 39: 377-80.

87 Dutton J J, Burde R M, Klingele T G. Autoimmune retrobulbic optic neuritis. Am $\mathcal{f}$ Opthalmol 1982; 94: $11-4$.

88 Barile L, Lavalle C. Transverse myelitis in systemic lupus erythematosus - the effect of IV pulse methylprednisolone erythematosus-the effect of

89 Sergent J S, Lockshin M D, Klempner M S, Lipsky B A. Central nervous system disease in systemic lupus Central nervous system disease in syst

90 O'Connor J F. Psychoses associated with systemic lupus erythematosus. Ann Intern Med 1959; 51: 526-36.

91 McCune W J, Golbus J, Zeldes W, Bohlke P, Dunne R, Fox D A. Clinical and immunological effects of monthly administration of intravenous cyclophosphamide in severe systemic lupus erythematosus. NEngl f Med 1988; 318: 1423-31.

92 Boumpas D T, Yamada H, Patronas N J, Klippel J H, Balow J E. Pulse cyclophosphamide for severe neuropsychiatric lupus. Qf Med 1991; 296: 975-84.

93 Smith $H$, Hansen $C$ L, Rose $R$, Canoso $R T$. Autoimmune MRL-1 pr/1 pr are an animal model for the secondary antiphospholipid syndrome. F Rheumatol 1990; 17: 911-5. 